\title{
OS DIREITOS BÁSICOS COMO DIREITOS HUMANOS EM HENRY SHUE
}

Edegar Fronza Junior ${ }^{1}$

\begin{abstract}
RESUMO
O presente artigo apresenta e discute a teoria de Henry Shue sobre os direitos básicos. Para o autor, os direitos básicos à segurança, subsistência e liberdade são essenciais para o aproveitamento efetivo dos demais direitos. A fundamentação substantivada da teoria de Shue considera os direitos humanos como meios para garantir as condições mínimas necessárias para as respectivas formas de vida. Shue afirma que a falha em reconhecer um direito mínimo a subsistência se encontra na falsa dicotomia defendida por algumas concepções entre direitos positivos e negativos. Por exemplo, a posição libertária defende que os direitos sociais não seriam direitos genuínos porque impõem aos outros deveres positivos. O presente artigo pretende defender que um direito humano básico impõe deveres positivos, bem como, deveres negativos. Se os direitos humanos geram deveres positivos, precisamos saber quais são as pessoas e/ou instituições responsáveis por esses deveres. Pretende-se mostrar que a proposta de Shue apresenta uma resposta para essas questões e uma contribuição para a defesa do reconhecimento e implementação da prática dos direitos sociais.
\end{abstract}

Palavras - Chave: Henry Shue; Direitos básicos; Direitos Humanos

\footnotetext{
${ }^{1}$ Bacharel em Filosofia pela Faculdade São Luiz (2011). Licenciado em Filosofia pela Universidade Federal de Santa Catarina (2015). Bacharel em Teologia pela Faculdade Católica de Santa Catarina (2015). Bolsista da CAPES/CNPQ. Mestrando do Programa de Pós Graduação em Filosofia da Universidade Federal de Santa Catarina. Atualmente desenvolvendo pesquisa sobre tolerância, reconhecimento, emancipação, justiça e democracia em Rainer Forst.
} 


\begin{abstract}
This article presents and discusses the Henry Shue's theory of basic rights. For the author, the basic rights to security, livelihood and freedom are essential for the effective use of other rights. The substantivized grounds of Shue theory considers human rights as a means to ensure the minimum conditions necessary for their life forms. Shue argues that the failure to recognize a minimum right to subsistence is the false dichotomy advocated by some views between positive and negative rights. For example, the libertarian position advocates that social rights were not genuine rights because they impose positive duties to others. This article intends to argue that a basic human right imposes positive duties, as well as negative duties. If human rights generate positive duties, we need to know what are the people and / or institutions responsible for these duties. It is intended to show that the proposed Shue has an answer to these questions and a contribution to the defense of the recognition and implementation of social rights practice.
\end{abstract}

Key Words: Henry Shue ; Basic rights ; Human rights 


\section{INTRODUÇÃO}

Em sua obra Basic Rights, Henry Shue defende que há alguns direitos que devem ser satisfeitos antes de quaisquers outros, a saber, os chamados direitos básicos. Eles são os direitos à segurança, subsistência e liberdade. Tais direitos seriam precondições para os demais, pois sem eles, o cumprimento dos outros direitos seria impossível. Eles asseguram algumas necessidades básicas fornecendo uma proteção mínima contra o total desamparo de modo a proteger a população vulnerável contra ameaças devastadoras. Deste modo, os direitos humanos básicos possuem o papel de restringir as forças econômicas e políticas e fornecem um padrão mínimo ao qual nenhum indivíduo deverá ficar abaixo.

A defesa dos direitos morais como direitos básicos e, por conseguinte, dos direitos humanos, representa uma importante contribuição para as chamadas teorias denominadas por Forst de justificações éticas dos direitos humanos. Estas se caracterizam por colocarem em primeiro plano as concepções substantivas de bem-estar ou de "vida boa", e considerarem os direitos humanos como meios para garantir as condições mínimas necessárias para as respectivas formas de vida. O ser humano que aqui está no centro é aquele interessado em realizar uma vida boa, e que tem direito a ela, os direitos humanos devem tornar isso possível para cada pessoa.

A posição libertária tradicional defende que os únicos direitos verdadeiros são direitos negativos, isto é, direitos que impõem deveres de não interferência, por exemplo, os direitos de liberdade. Para esta posição, os direitos sociais, tais como, o direito humano às necessidades básicas, não seriam direitos genuínos porque impõem deveres positivos. Shue afirma que a falha em reconhecer um direito mínimo a subsistência se encontra nessa falsa dicotomia entre direitos positivos e negativos. Para Shue, qualquer direito humano básico vai impor deveres positivos, bem como, deveres negativos. No lugar dessa dicotomia, ele desenvolve um conjunto de deveres correlativos aos três direitos básicos, a saber, 1) deveres de não privar o titular do direito do objeto do direito, 2) deveres para proteger os titulares de direitos contra essas privações e 3) deveres para ajudar aqueles que já tenham sido privados (SHUE, 1980, p. 53).

O presente artigo pretende fazer uma análise da teoria de Henry Shue e discutir que tipos de deveres os direitos sociais podem gerar. Se os direitos humanos gerarem deveres positivos e não apenas deveres negativos, precisamos saber quais são as pessoas e/ou instituições 
responsáveis por esses deveres positivos. Pretende-se mostrar que a proposta de Shue apresenta uma resposta para essas questões e uma contribuição para a defesa do reconhecimento e implementação prática dos direitos sociais.

\section{A DEFINIÇÃO DE DIREITOS MORAIS COMO DIREITOS BÁSICOS}

O principal argumento de Shue para defender o direito à subsistência fundamenta-se numa concepção moral de um direito básico. Logo no início do primeiro capítulo, Shue apresenta sua concepção de direito moral: "Um direito moral fornece (1) a base racional para uma demanda justificada (2) do gozo efetivo de uma substância sendo(3) socialmente garantida contra ameaças padrão" (SHUE, 1980, p. 13). O relato acerca da definição de direito moral merece alguns esclarecimentos tendo em vista sua complexidade.

Inciemos, então, pela primeira parte da definição, isto é, "Um direito moral fornece a base racional para uma demanda justificada". O que Shue pretende enfatizar a partir desse primeiro enunciado é a ideia de que um direito moral só é válido se existe uma base racional que justifica a sua demanda. Se o cidadão possui alguns direitos, então, ele deve poder gozar dos mesmos dada sua justificação que possibilita que tais garantias sejam asseguradas. Nas palavras de Shue "uma pessoa que tem um direito tem razões especialmente atraentes princípios profundos ao seu lado" (SHUE, 1980, p. 13).

O direito na perpesctiva de Shue possui o sentido de exigência que se funda em vista de uma necessidade justificada de algo ${ }^{2}$. Por que o direito é a base de uma demanda justificada que deve insistir, exigir, reclamar, insistir. Isso, no entanto não quer dizer que necessariamente tais petições serão prontamente atendidas sem nenhuma restrição. Os direitos não são meras petições ou exigências, mas conduzem a demandas que se fundamentam em última instância na dignidade dos seres humanos. Nao são portanto, meros presentes, pedidos ou favores entregues de modo benevolente ou por piedade, como num ato de caridade, antes constituem-se indispensavéis bens valiosos. Shue cita Joel Feinberg.

Um direito é algo que pode ser exigido ou insistindo sem constrangimento ou vergonha quando isso a que se tem direito não é iminente, a reação apropriada é a

\footnotetext{
${ }^{2}$ Rainer Forst em sua obra Justification and Critique parece corroborar com a tese de Shue acerca do direito como justificação racional mediante uma demanda existente: "O fundamento moral dos direitos humanos, tal como o reconstruo, é o respeito à pessoa moral como agente autônomo com um direito à justificação, isto é, um direito a ser reconhecido como alguém que está moralmente justificado a reivindicar qualquer ação e que pode exigir razões adequadas para toda estrutura política ou social ou para toda lei que pretenda vinculá-lo" (FORST, 2011, p. 46).
} 
indignação; quando é devidamente entregue, não há razão para a gratidão, uma vez que é simplesmente por conta própria ou a própria função de quem o recebeu. Um mundo com a afirmação de direitos é aquele em que todas as pessoas, como demandante efetivo ou potencial, são objetos dignos de respeito, tanto em seus próprios olhos e na visão de outros. Nenhuma quantidade de amor e compaixão, ou a obediência à autoridade superior, ou nobre obrigação, pode substituir esses valores (FEINBERG apud SHUE, 1980, p. 15).

A partir da ideia de direito como uma exigência (claim), Shue desenvolve o seu arcabouço conceitual que acrescenta na segunda parte da definição dos direitos morais como "gozo efetivo de uma substância". Através dessa afirmação, o filósofo quer deixar clara a ideia de que um direito não pode ser proclamado sem que o cidadão possa efetivamente gozá-lo. Em linhas gerais, refere-se a ideia de que, por exemplo, ao anunciar o direito à liberdade, os cidadãos podem desfrutar da liberdade, apreciando-a de modo a fazer com que sua substancialidade enunciada na lei possa de fato ser concretizada. É o que o autor chama de substância do direito, portanto seu gozo efetivo.O gozo efetivo da substância do direito deve ser socialmente garantido contra ameaças padrão. O ser socialmente garantido estabelece a relação entre direitos e deveres correlativos que implicam a não exclusão de nenhum grupo social.

A terceira parte da definição de direito moral está preocupada com as situações em que os diretios básicos possam ser violados, por isso a premissa central de que "pessoas relevantes ou instituições" devem fornecer o mínimo raozável ${ }^{3}$ de proteção contra tais privações. Isso inclui, a criação de normas e leis que sejam eficazes contra ameaças padrão. Embora não seja necessário que todo o direito moral tenha todas as três características, todo o direito básico deve garantias sociais contra ameaças padrão. A respeito dessa universalidade dos direitos a partir das standard threat, Shue comenta:

O que é universal, no entanto, é um dever de fazer e manter mecanismos eficazes e minha análise tríplice de deveres correlativos irá sugerir que estes mecanismos devem servir pelo menos as funções de evitar privar as pessoas dos conteúdos dos seus direitos, protegendo-os contra a privação e auxiliando-os se eles são privados dos direitos. O que agora estou chamando de dever de desenvolver e preservar instituições eficazes para o cumprimento dos direitos é um resumo de grande parte do que está envolvido na realização de todos os três deveres correlativos aos direitos comuns (SHUE, 1980, p. 17-18).

\footnotetext{
3 O conceito razoável provavelmente extraído do vocabulário rawlsiano, refere-se a termos equitativos de cooperação e a possibilidade de aceitação pública de valores compartilhados a fim de expressar uma concepção inteligível de mundo frente à multiplicidade de juízos e doutrinas abrangentes.
} 
Em suma os direitos morais na concepção de Shue devem ser considerados direitos básiscos por refirirem-se a demandas racionalmente justificadas e efetivamente gozadas, devendo ser assegurados frente a violações e privações procedentes de ameaças padrão.

\section{OS DIREITOS BÁSICOS}

Com a defesa dos direitos morais como sendo direitos básicos, entendemos que uma das grandes preocupações de Shue ao escrever a sua obra é a necessidade de assegurar direitos básicos a fim de fornecer o mínimo de proteção aos mais fracos e desamparados. Os direitos básicos referem-se em última instância a um mínimo necessário sem o qual nenhum ser humano deve estar submetido, a fim de evitar privações contra ameaças reais. A terminologia escudo é utilizada em sua teoria para indicar o poder de veto/proteção que os direitos básicos teriam frente a coerção de governos ditatoriais e totalitaristas.

De acordo com Shue, o que é distintivo nos direitos básicos é a ideia de que o gozo dele é essencial para os demais direitos. Sem eles não pode haver o cumprimento dos outros direitos. Enquanto direitos não básicos poderiam ser sacrificados em vista de outros direitos básicos, estes últimos não poderiam ser sacrificados em vista de direitos dos primeiros.

\footnotetext{
Direitos básicos são pedidos razoáveis mínimos de todos sobre o resto da humanidade. Eles são a base racional para demandas justificadas a negação de que nenhuma pessoa que se preze pode razoavelmente esperar que aceitar. Por que deveria haver algo tão importante? A razão é que os direitos são básicos no sentido usado aqui, apenas se o gozo deles é essencial para o gozo de todos os outros direitos. Isto é o que é distintivo sobre um direito básico. Quando um direito é realmente básico, qualquer tentativa de desfrutar de qualquer outro direito, sacrificando o direito básico seria, literalmente, autodestrutivo, cortando o chão debaixo de si. Portanto, se um direito é básico, outros direitos, nãobásicos podem ser sacrificados, se necessário, a fim de garantir o direito de base. Mas a proteção de um direito fundamental não pode ser sacrificado, a fim de garantir o gozo de um direito não-básico (SHUE, 1980, p. 19).
}

O que Shue pretende postular com sua teoria é que não basta apenas a existência de um direito, mas é preciso que este realmente seja efetivado, ou seja, que o cidadão possa desfrutá-lo. Por isso, em certo sentido o filósofo abadona a dicotomia entre direitos positivos e direitos negativos e acaba estabelecendo uma lista tríplice de direitos com seus respectivos deveres. $\mathrm{O}$ tripé segurança, subistência e liberdade são os direitos fundamentais para que possa haver o gozo dos demais direitos. 
Um direito básico é afirmado sendo necessário para o gozo de outros direitos. A estrutura do argumento de um direito básico pode ser resumida da seguinte forma, desde que sejamos cuidadosos sobre o que se entende por "necessário".

1. Toda pessoa tem direito a alguma coisa;

2. Algumas outras coisas são necessárias para desfrutar a primeira coisa como um direito, seja qual for a primeira coisa;

3. Por isso, todo mundo também tem direitos para as outras coisas que são necessárias para desfrutar o primeiro como um direito (SHUE, 1980, p. 31).

Dois pontos importantes sobre esta estrutura argumento são esclarecidas por Shue. Em primeiro lugar, o argumento "é baseado no que normalmente significa que qualquer coisa seja um direito ou, em outras palavras, sobre o conceito de um direito". O conceito de um direito moral, foi caracterizado em termos de uma demanda justificada do gozo de uma substância ser socialmente garantida. Por isso, a segunda premissa e a conclusão incluem a noção de "desfrutar a primeira coisa como um direito. A inclusão desta noção na estrutura de argumento irá desempenhar um papel central na crítica do argumento de Shue. ${ }^{4}$

Com a sua teoria dos direitos básicos, Henry Shue propõe um modo de atribuir prioridade entre os direitos. Para ele, há alguns direitos morais básicos que devem ser satisfeitos antes de outros. Os direitos básicos de segurança, subsistência e liberdade devem ter prioridade porque são precondições de todos os outros direitos. Sem eles, o cumprimento dos outros direitos seria impossível. Por exemplo, o direito de liberdade de religião não será usufruído se alguém sofrer violência física ou se for assassinado. Então, a segurança é um direito básico não somente porque é valioso em si mesmo, mas porque nenhum outro direito poderá ser usufruído se a segurança física não for protegida. A seguir, os direitos básicos serão analisados.

\subsection{Direitos de Segurança}

O direito básico de segurança em Shue se adequa perfeitamente ao artigo terceiro da Declaração Universal dos Direitos Humanos: “Todo indivíduo tem direito à vida, à liberdade e à segurança pessoal”(DECLARAÇÃO UNIVERSAL DOS DIREITOS HUMANOS). De um modo geral, toda a obra de Shue desenvolve em certa medida estas três categorias, a saber: vida, liberdade e segurança.

\footnotetext{
${ }^{4}$ Cf. PAYNE, Michael. Henry Shue on Basic Rights. In: Essays in Philosophy. Jun. 2008. N.2. Vol. 9.
} 
O direito de segurança é fundamental para que se assegurem os demais direitos. Tratase de um direito não apenas negativo, ou seja, de não intervenção na vida dos demais indivíduos, mas assegurado positivamente. A fundamentação dada por Shue baseia-se na seguinte afirmação:

Ninguém pode desfrutar plenamente o direito que supostamente está protegido pela sociedade se alguém pode de ameaçar-lhe com assassinato, estupro, espancamento, etc., quando ele ou ela tenta aproveitar o suposto direito. Tais ameaças à segurança física estão entre os mais graves e em grande parte do mundo os obstáculos mais comuns para o gozo de qualquer direito. Se qualquer direito deve ser exercido, exceto em grande risco, a segurança física deve ser protegida (SHUE, 1980, p. 21).

Shue deixa claro através dessa passagem que na ausência de segurança física as pessoas são incapazes de utilizar os demais direitos. O que está subjacente à falta do direito à segurança é olhar atento para as formas de governo tirânicas que por vezes utilizaram-se da força para coerção dos indivíduos. A barbárie que se manifestou através da tortura e holocausto de milhares de pessoas no mundo todo não pode ser repetida, por isso a necessidade de garantir a segurança física não apenas como direito negativo, mas também como um direito básico.

\subsection{Direitos de Subsistência}

O direito básico à subsistência encontra-se paralelo ao direito de segurança. Ora, se existe um direito à segurança que não é apenas negativo, mas positivo, por que não poderia haver um direito à subistência também positivo? O direito à subistência mínima afeta diretamente o que Shue destaca logo no início de sua obra em relação ao não reconhecimento de direitos positivados na Constituição dos Estados Unidos. No discurso de 1977, conhecido como Política de Direitos Humanos, o então secretário de governo define o que entende por direitos humanos:

Existe o direito ao cumprimento de tais necessidades vitais como alimentos, abrigo, cuidados de saúde e educação. Nós reconhecemos que o cumprimento deste direito dependerá, em parte, do estágio de desenvolvimento econômico de uma nação. Mas também sabemos que esse direito pode ser violado por ação ou omissão, por exemplo de um Governo, através de processos de oficiais corruptos que desviam recursos para uma elite à custa dos necessitados, ou através de indiferença para com o sofrimento dos pobres (apud SHUE, 1980, p. 5).

O direito à subistência, no sentido tratado por Shue é um tipo de segurança econômica que implica numa lista de necessidades a serem atendidas como ar puro, água não poluída, 
alimentação adequada, vestuário adequado, abrigo adequado e cuidados de saúde pública preventiva mínima (SHUE, 1980, p. 23). É verdadeiro, no entanto, que os diferentes autores teriam dificuldade em especificar esta lista de direitos básicos entendidos como subistência. Alguns até mesmo questionariam quais critérios norteiam a escolha de tais direitos na perspectiva de nosso autor. ${ }^{5}$

A principal ideia a ser levada em consideração sobre os limites exteriores da proposta do direito à subsistência leva em consideração dois critérios importantes. O primeiro refere-se à subistência como o "consumo que é necessário para uma boa chance de ter uma vida razoavelmente saudável e ativa mais ou menos normal de ser cumprida, impedindo intervenções trágicas" (SHUE, 1980, p. 23). O segundo está relacionado a incapacidade de se manter, ou seja, “inclui o fornecimento de subsistência, pelo menos para aqueles que não podem fornecer para si mesmos" (SHUE, 1980, p. 24). Isto inclui de modo particular crianças e pessoas em situação de extrema vulnerabilidade social.

Shue chama atenção da corrupção que perpassa pessoas e instituições que se utilizam dos bens indevidamente e colhendo benesses dos mesmos. Para o filósofo, todos as pessoas e grupos sociais são proibidos de simplesmente tomar mais do que eles precisam para sobreviver. Além disso, critica as leis que não possibilitam a apropriação dos direitos mínimos de subsistência.

Quaisquer que sejam as instituições de propriedade e do sistema econômico, a questão sobre os direitos à subsistência permanece: se as pessoas são proibidas por lei de tomar o que elas precisam para sobreviver e eles são incapazes dentro das instituições e das políticas econômicas existentes para garantir a sua própria sobrevivência (e a sobrevivência de dependentes para cujo bem-estar são responsáveis). Não é deles o direito o direito, como um último recurso, para receber os elementos essenciais para a sobrevivência do restante da humanidade, cujas vidas não estão ameaçadas? (SHUE, 1980, p. 24)

As mesmas considerações que suportam a conclusão de um direito à segurança física devem ser entendidas como um direito básico, pois dão base argumentativa para que o direito a subsistência como uma proteção econômica possa ser aceita. Deste modo, o direito à subsistência se valida tendo como lógica a seguinte afirmação.

\footnotetext{
${ }^{5}$ Muitos críticos argumentam que de fato esses direitos mínimos são muito exigentes. Em particular, eles não respeitam as formas padrões de raciocínio que temos discutido sobre $s e$ os direitos políticos e civis terem prioridade sobre os direitos sociais e econômicos (WIDDOWS, Heather. Global Ethics. Acumen, Durham U.K., 2011 , p. 116 ).
} 
Ninguém pode totalmente, em tudo, desfrutar de qualquer direito que supostamente está protegido pela sociedade, se ele ou ela não tem os elementos essenciais para uma vida razoavelmente saudável e ativa. Deficiências nos meios de subsistência podem ser tão fatais ou incapacitantes, ou dolorosas como violações de segurança física. $\mathrm{O}$ dano ou morte resultante pode ao menos tão decisivamente impedir o gozo de qualquer direito como podem os efeitos de violações de segurança. Qualquer forma de desnutrição, ou febre devido à exposição, que provoca graves danos cerebrais irreversíveis, por exemplo, pode efetivamente impedir o exercício de qualquer direito que exige pensamento claro e pode, como lesões cerebrais causadas por assalto, prejudicar profundamente uma pessoa. Pessoas que não têm proteção contra as violações de sua segurança física podem, se eles são livres, lutar contra seus agressores ou fugir, mas as pessoas que carecem de fundamentos, tais como alimentos, devido a forças além de seu controle, muitas vezes não podem fazer nada e estão totalmente impotentes. (SHUE, 1980, p. 24).

A garantia de segurança e subsistências são necessidades inerentes e fundamentais para o exercício dos demais direitos. Não se trata de entender que um direito é meramente um meio para um fim, mas que a lista tríplice dos direitos se perpassam. Pois, não é que a segurança de violência física, por exemplo, se separada da liberdade de reunião pacífica, mas que sempre precisa acompanhá-la. Ter segurança física para realizar uma reunião faz parte de ser livre para organizá-la. Se não se pode organizá-la com segurança, não é livre para reunir-se.

\subsection{Direito à liberdade}

A última parte da lista dos direitos básicos do primeiro capítulo trata do direito à liberdade. Shue não pretende inflacionar o conceito tratando-o de modo exaustivo. Pelo contrário, ao abordar a liberdade como direito básico quer referir-se ao gozo de algo fundamental para o exercício dos demais direitos. ${ }^{6}$

Num primeiro momento, Shue insere a discussão do terceiro direito básico no panorama da convergência entre os países do Atlântico norte, chamados de "amigos da liberdade" e os países mais pobres, acerca da teoria do trade-off. Em linhas gerais a teoria do trade-off é uma

\footnotetext{
${ }^{6}$ No intuito de definir o conceito de liberdade na última parte do terceiro capítulo Shue comenta: "Não estou pedindo as formas mais ricas ou mais elevadas de liberdade, julgados por ideais morais da boa vida ou uma boa sociedade. Sem dúvida, existem tipos de liberdade que são necessárias para, digamos, a expressão artística e cultural de valor inestimável para as formas mais altas da sociedade. Mas se o exercício dessas liberdades não é necessário para o exercício de todos os direitos, essas liberdades não são direitos básicos, no entanto eles são importantes por outras razões. Minha preocupação agora é determinar não a maior, mas os mais básicos, tipos de liberdade. Eu estou aqui, como em outras partes deste livro, trabalhando sobre os alicerces, e não os pináculos, do edifício dos direitos. As liberdades básicas vão passar a incluir a liberdade de participação" (SHUE, 1980, p. 70).
} 
expressão que define uma situação em que há conflito de escolha que se caracteriza em uma ação econômica que visa à resolução de problemas mas acarreta outros, obrigando uma escolha. Ocorre quando se abre mão de algum bem ou serviço distinto para se obter outro bem ou serviço distinto.

A liberdade, ganha maior amplitude, a partir dessa perspectiva, pois se insere no contexto das realidades dos países mais pobres, onde as liberdades precisam ser sacrificadas em vista do desenvolvimento econômico e social. A esse respeito o próprio Shue denuncia:

Em países do terceiro mundo que sofrem de pobreza, o analfabetismo generalizado é um fosso na distribuição interna dos rendimentos e da riqueza, a liberdade constitucionalmente garantida de oposição e discordância pode não ser tão significativa como a liberdade do desespero, doença e privação. As massas podem realmente ser muito mais felizes se eles pudessem colocar mais em suas bocas que palavras vazias; se elas pudessem ter um centro de saúde, em vez de canto Hyde Park; se a eles fossem assegurados emprego remunerado em vez do direito de marchar sobre a capital. Os trade-offs podem ser desanimadores e desagradáveis para um purista Ocidental, mas podem ser necessários ou inevitáveis para a maioria dos Estados-nação (SHUE, 1980, p. 66).

A liberdade é um direito irrenunciável e inalienável na teoria de Shue, pois para o desenvolvimento de um país não basta apenas fornecer alimentos, vestuário e abrigo. Até mesmo uma prisão pode fazer isso. O desenvolvimento implica, em certo sentido, na escolha dos alimentos, do vestuário e do abrigo a ser fornecido. A liberdade não se restringe apenas a livre circulação de pessoas, mas a uma política que permita a participação de todos de modo igual.

A liberdade não pode ser apenas uma promessa da boa vontade advinda de governantes e nações, como uma entidade metafísica ou mesmo uma peça de museu a ser apreciada. Ela se efetiva através de meios adequados aos quais tem por base os direitos de subsistência e segurança, sem os quais não pode ser garantida. Deste modo pode-se afirmar que "é fraudulenta para confortar as pessoas com promessas de liberdade que não pode realmente desfrutar, porque os componentes necessários do gozo, como proteção para a segurança física, estão faltando. É fraudulenta, em outras palavras, a promessa de liberdades na ausência de segurança, subsistência, e quaisquer outros direitos básicos” (SHUE, 1980, p. 69).

É importante notar, no entanto, que há uma chamada interdependência dos três direitos básicos que são uma via de mão dupla, pois ao passo que segurança e subsistência são essenciais para o real aproveitamento das liberdades, a efetivação e gozo de determinadas liberdades são fundamentais para que segurança e subsistência sejam garantidas. 


\subsubsection{Liberdade de participação}

O tema da liberdade de participação pode ser formalizada em duas questões: A participação é universalmente desejada? E ainda, a participação é universalmente necessária? É importante considerar, no entanto, que o tema da liberdade de participação, na perspectiva de nosso filósofo não se restringe ao sentindo meramente político.

A primeira acepção feita por Shue é a ideia do foco da participação, que refere-se às escolhas fundamentais entre as instituições sociais e as políticas sociais que controlam a segurança e subsistência, ligando-se diretamente ao modo como as pessoas são afetadas pelo funcionamento das instituições e a implementação da política. Para o filósofo, sem uma real influência sobre detalhes de implementação e operação, a ação é ineficaz. Por outro lado, não é realista dizer que todos têm direito a influenciar a todos os detalhes.

A segunda ideia trazida acerca da participação relaciona-se a uma real influência sobre os resultados, evitando quaisquer tipos de pseudoparticipação ou participação parcial. Obviamente, não se pode exigir que a participação genuína sempre produzirá o resultado desejado, mas isso não é desculpa suficiente, para que as pessoas sejam ouvidas, mas não atendidas.

A terceira distinção que Shue faz sobre o conceito de participação é alargar o seu arcabouço de entendimento para além do seu sentido político. Isso por que, muitas questões envolvem a participação que ultrapassam o sentido meramente político, por vezes pode até se entrelaçar com este último, mas não se restringe a ele. O restante da vida é tão influenciado por organizações econômicas, como oligopólios corporativos domésticos e corporações transnacionais gigantescas, como por governos e organizações estritamente políticas.

Duas considerações precisam ser feitas ao tratar da participação efetiva como direito básico. Em primeiro lugar muitas pessoas, na verdade, não estão interessadas na participação, nas escolhas fundamentais sobre as instituições sociais ou políticas sociais, mesmo se o cumprimento de seus próprios direitos é afetado. E em segundo lugar, muitas pessoas não querem participar a fim de gozar da substância de seus direitos básicos, por que não acreditam ser necessários para si.

A questão subjacente é: Quando um direito pode ser considerado universal? Tendo em vista que algumas pessoas podem não o achar necessário ou não ter interesse por ele. Bastaria 
apenas a consideração que de um direito é legítimo quando as pessoas em todos os lugares pensam nisso como um direito?

Em algumas sociedades camponesas tradicionais, a estrutura social foi fortemente hierárquica e, em cada comunidade, o principal proprietário tomou as decisões fundamentais até mesmo sobre os direitos básicos de segurança e de subsistência. Além disso, em pelo menos algumas dessas comunidades, as decisões específicas feitas chegaram a fornecer tanto segurança quanto subsistência. O proprietário fez com que seus trabalhadores estivessem a salvo da miséria e ataques, e eles estavam satisfeitos por desfrutar de sua segurança de estadia e serem livres de preocupações com providências necessárias. E pode-se tentar imaginar uma ditadura benevolente paternalista sobre uma sociedade moderna em que as pessoas são livres de privação ou, quando a proteção falha, são assistidos em superar sua falta de segurança ou a subsistência; instituições e as políticas são inteiramente concebidas pelo ditador e seus "especialistas"; e as pessoas, bem como o ditador, estão satisfeitos com os resultados do regime (SHUE, 1980, p. 72).

Embora a premissa de que muitas pessoas estão desinteressadas em participar da escolha de seus direitos fundamentais seja verdadeira, não se segue a inferência que a participação não pode ser um direito universal. Não é uma condição necessária para algo ser um direito universal que haja uma crença universal sobre um direito. As pessoas podem ter direitos que elas não sabem que tem. Alguns escravos, por exemplo, podem esperar e aceitar agressões de seus senhores, eles podem acreditar que os mestres tem um direito-dever em relação a "disciplina" deles. Se assim for, os escravos estão enganados sobre sua crença: não existe o direito de possuir ou de violar a segurança física de outro ser humano. Crenças sobre direitos podem estar incorretas, assim como crenças sobre quase todos os outros indivíduos podem seguir a mesma lógica.

A questão acerca da justificação racional dos direitos parece estar em relevo na discussão. ${ }^{7}$ A esse respeito Shue comenta.

Quais direitos e deveres correlativos, as pessoas têm é determinado pelo peso de suas razões. Se as razões para o acordo a todos os direitos particulares são fortes o suficiente, todos tem esse direito, e todos os outros e todas as organizações e instituições deveriam, pelo menos evitar violá-lo, e alguns outros deveriam proteger e assistir as pessoas privadas do mesmo. Se os motivos de acordo com ele são muito fracos, não existe tal direito geral. A fim de decidir quais os

\footnotetext{
${ }^{7}$ Esse ponto comum compartilhado por Forst na obra citada no início do presente artigo. A ideia geral de que os direitos humanos devem buscar sua justificação racional perante os indivíduos a fim de evitar a dominação tirânica e despótica.
} 
direitos que existem deve-se avaliar a qualidade de raciocínio, não a quantidade de crença (SHUE, 1980, p. 73).

Dizer que as pessoas podem ter direitos, independentemente de elas acreditarem que tem, precisa ser claramente distinguido de dizer que as pessoas devem exercer os direitos que têm independentemente de se elas querem exercê-los. Que eu tenho o direito de liberdade de movimento, por exemplo, não significa que eu devo constantemente ou nunca me mover, se eu não quiser. Alguns direitos, na verdade, deveriam ser exercidos, por exemplo, o direito a uma educação pública por aqueles que não podem dar ao luxo de pagar por um privado, que é melhor do que o público disponível. Mas qualquer dever, se houver, para tirar proveito de um direito que você tem não seria um correlato dever para a direita, mas um tipo de dever bem diferente que flui de um ideal moral de uma vida rica. Tais ideais e suas funções associadas podem também ser importantes, mas não são simplesmente parte de uma teoria dos direitos. Se as pessoas devem, como parte de uma vida idealmente completa, querer participar nas instituições e políticas que controlam o cumprimento dos seus direitos é uma questão importante. Mas é uma questão diferente se elas tem um direito básico para participar caso queiram ou até mesmo se optarem por não participar (SHUE, 1980, p. 73-74).

O segundo ponto do argumento sobre a participação efetiva é mais complexa do que a primeira. Isso por que, enquanto a primeira fundamenta-se no não querer participar, esta desloca a discussão para a não necessariedade da participação, tendo em vista o não gozo efetivo dos direitos básicos anteriores ao da participação. A fim de elucidar a questão, Shue questiona: alguns despotismos, que permitem pouca ou nenhuma participação, não oferecem segurança, subsistência, e algumas outras substâncias de direitos de suas populações? É a participação realmente necessária então, para a recepção de outros direitos? Será que o exemplo de um despotismo esclarecido que fornece segurança e subsistência não mostram que a participação não é estritamente necessária? (SHUE, 1980, p. 74).

Para responder as inquirições elencadas precisamos de uma firme concepção bem definida do que significa desfrutar um direito. Como vimos logo no início do artigo, um direito fornece (1) a base racional para uma demanda justificada (2) do gozo efetivo de uma substância ser (3) socialmente garantida contra ameaças padrão. Isso significa que a apreciação deve ser socialmente garantida. O regime deveria ter sido feito por ou com auxílio das demais pessoas, evitando situações em que uma pessoa ou instituições mantenham atitudes arbitrárias sobre determinadas decisões, com finalidade de tirar proveito pessoal as custas do direitos de outrem. Nas palavras de Shue: "Um suposto direito que não inclui uma exigência de garantias sociais, no 
sentido de arranjos feitos por, ou com, alguns ou todo o resto da humanidade, seria um direito sem deveres correlativos, nada exigindo de outros, e isso não seria um direito normal, mas algo mais parecido com um desejo, um sonho, ou uma súplica" (SHUE, 1980, p. 75).

O prazer da essência do direito é socialmente garantida, apenas se todas as instituições sociais, bem como pessoas individuais, não privarem as pessoas da essência do direito, e somente se algumas instituições sociais (local, nacional ou internacional) protegerem as pessoas contra a privação da essência do direito e alguns fornecerem, se necessário, a ajuda a qualquer pessoa que tenha sido privada da substância do direito. "Uma pessoa está realmente desfrutando de um direito apenas se está vivendo entre instituições sociais que são bem desenhadas para impedir violações do direito e, quando a prevenção falha, para restaurar o gozo do direito na medida do possível" (SHUE, 1980, p. 75).

Poderíamos nos perguntar então, se é verdade que alguém pode desfrutar de um direito à segurança e à subsistência sem ausência de direitos para uma verdadeira influência sobre as escolhas fundamentais entre as instituições e as políticas de controle de segurança. A resposta é não. É impossível desfrutar de todos os direitos para a segurança ou para subsistência sem também ter o direito de participar efetivamente do controle da segurança e subsistência. Um direito é a base para certo tipo de demanda: uma demanda cujo cumprimento deveria ser socialmente garantida. Sem canais através dos quais a demanda pode ser dada a conhecer a quem deveria, assegurando sua garantia o seu cumprimento, este direito não pode ser direito.

O exemplo do déspota esclarecido, apesar da aparente benevolência não é uma boa elucidação da participação efetiva das pessoas. O que falta ao déspota esclarecido são instituições que possuam deveres correlativos $^{8}$ como, por exemplo, proteção contra a privação pelo próprio governo. Neste caso a participação é um componente não só da prevenção de privação de direitos, mas também das modalidades de obtenção do auxílio quando as violações ocorreram.

O que Shue quer alertar através do exemplo do ditador é que contra a privação por um ditador anteriormente benevolente, nenhuma defesa pode ser possível na ausência de formas estabelecidas de participação disponíveis para vítimas. A autoridade se torna juiz oficial de que os direitos existem e o meio para cumpri-los, o que quer dizer que não existem direitos a qualquer coisa.

\footnotetext{
${ }^{8} \mathrm{O}$ ditador pode, evidentemente, proporcionar segurança, subsistência, ou ambos, em qualquer momento dado, mas simplesmente para proporcionar algo que não é o mesmo que fornecer como um direito. Para oferecer algo como um direito significa fornecer garantias sociais para a sua fruição contra ameaças padrão, e essas garantias devem incluir mecanismos adequados para o desempenho eficaz de todos os três tipos de deveres correlativos (SHUE, 1980, p. 76).
} 


\subsubsection{Liberdade de movimento físico}

A discussão até o presente momento tem se concentrado em certo tipo de liberdade pensada como participação no controle das políticas e instituições econômicas que determinam o cumprimento de segurança, subsistência, e outros direitos. No entanto, poderíamos nos questionar: "Há outro tipo de liberdade que deva ser assegurado a fim de possibilitar o gozo efetivo dos demais direitos básicos?" Sim, a liberdade de movimento físico.

A liberdade física refere-se à ausência de restrições arbitrárias sobre partes do corpo tais como cordas, correntes e camisas de força nos membros e sobre o movimento de um lugar para outro de todo o nosso corpo, tais como encarceramento a residência.

$\mathrm{Na}$ ausência do direito à liberdade de movimento físico, as pessoas podem desfrutar das substâncias de muitos direitos. Mas eles não podem apreciá-los como direitos, mas somente como privilégios, prerrogativas, indulgências. A privação pode ocorrer tão facilmente como disposição, e isso não é o mesmo que desfrutar de um meio certo. Um direito fornece a base para uma demanda cujo cumprimento deveria ser socialmente garantido, e um direito pode ser apreciado somente onde os indivíduos e instituições evitam privação protegendo contra relações arbitrárias de poder que possam interferir nesse direito essencial. E uma proteção eficaz deve incluir canais através dos quais aqueles cujos pedidos de direito não tenham sido satisfeitos, pode, de fato repetir e insistir em suas demandas até que sejam cumpridas. Shue argumenta:

Ninguém no estado de vulnerabilidade e dependência do arbitrariamente preso é em qualquer posição eficaz para fazer até mesmo as exigências para as coisas que são direitos. Os arbitrariamente presos estão à mercê dos seus captores. Eles não podem fugir e eles não podem lutar, e eles certamente não podem fazer exigências. Ser privado de liberdade de movimento físico é ser privado da independência essencial para o tipo de autoproteção necessária como parte de quaisquer instituições adequadas para a execução do dever de proteger (SHUE, 1980, p. 81).

A liberdade de movimento aparece no contexto da teoria de Shue como mais que necessário, não porém suficiente. Isso porque algo mais é necessário: segurança e subsistência. $\mathrm{O}$ que o filósofo pretende evitar ao evidenciar o tema da liberdade como participação e de movimento físico são as possíveis ditaduras paternalistas reformadas, ou seja, aqueles sistemas de governo ditatoriais que aparentemente beneficiam as pessoas com certos privilégios, mas não a empoderam. 
A aposta de Shue se encontra nas instituições como meio ao qual as pessoas podem recorrer para exigir seus direitos e ao mesmo tempo possibilitar o acesso a uma participação efetiva nas tomadas de decisões que interferem diretamente em suas vidas. É improvável, no entanto, que um regime ditatorial por mais paternalista e benigno que fosse propicie a participação direta na execução de direitos que as pessoas acreditassem possuir.

\section{A ELIMINAÇÃO DA DICOTOMIA ENTRE DIREITOS NEGATIVOS E DIREITOS POSITIVOS}

Shue argumenta que todos os direitos morais possuem aspectos positivos e negativos e que, portanto, não existem direitos puramente negativos ou positivos, mas apenas direitos "mistos". Assim, o direito fundamental à segurança física implica uma obrigação correlativa por parte de todos os outros para não violar a segurança física de uma pessoa. Shue acrescenta:

Mas é impossível proteger os direitos a segurança física de alguém sem fazer referência a uma ampla gama de ações positivas. Por exemplo, no mínimo, a proteção dos direitos à segurança física necessita de forças policiais; tribunais penais; penitenciárias; escolas para formação policial, advogados e guardas; e os impostos para suportar um enorme sistema de prevenção, detenção e punição de violações da segurança pessoal (SHUE, 1980, p. 37).

O direito positivo para a subsistência implica um dever correlato de outros para ajudar aqueles que não têm os meios de subsistência. A demanda para o cumprimento dos direitos de subsistência pode envolver não um fornecimento de bolsas de mercadorias, mas apenas alguma oportunidade para apoiar a si mesmo. Uma subsistência direta pode envolver nada mais do que uma demanda "para ser autorizado a ser auto-sustentável na base própria trabalho árduo. Assim, um direito positivo implica uma obrigação correlativa de não privar os outros de seu único meio de subsistência disponíveis, bem como o dever de auxiliar o privado" (SHUE, 1980, p. 55) .

Shue propõe que todos os direitos básicos tem um conjunto de três deveres correlativos: para não privar; para proteger da privação e para ajudar os desfavorecidos (SHUE, 1980, p. 60). A proteção por garantias sociais é a base para a rejeição da dicotomia direitos negativospositivos direitos, isso por que para Shue, os direitos sociais fazem parte do sentido comum do conceito de um direito moral.

O aspecto positivo de um direito básico de segurança física resulta da necessidade de proteção, e proteção é necessária para evitar a privação de uma subsistência. Sem proteção, o direito básico à segurança física seria um direito negativo, com deveres correlativos apenas para 
não privar uma pessoa de segurança física. Mais uma vez, sem proteção, o direito básico de subsistência seria um direito "misto", com deveres correlativos para não privar e para ajudar os desfavorecidos. Consequentemente, sem a exigência de proteção, a idéia básica da dicotomia direitos negativo-positivo permaneceriam intactos: somente um direito positivo incluiria uma obrigação correlativa para fornecer ajuda.

\section{CONCLUSÃO}

Ao apresentarmos a teoria de Shue sobre os direitos básicos nos deparamos com alguns questionamentos. O conceito de direito moral em Shue inclui um recurso ao exercício de um direito. Esta função é central em sua teoria dos direitos básicos. Isso por que tais direitos são definidos como necessários para o exercício dos demais direitos morais. Desse modo, poderíamos nos perguntar: "Se o gozo de um direito é característico do conceito de direito moral, então de onde se segue analiticamente o conceito de direitos básicos?” Todavia, se o exercício não é uma característica do conceito de direito moral, então, por definição, não há direitos básicos. Parece que o gozo não é uma característica do conceito de um direito moral. Há uma distinção bem aceita entre ter um direito e o exercício deste. Parece patente que uma pessoa pode ter um direito ao qual não pode exercer ou desfrutar. Assim, o exercício ou gozo não seguem analiticamente a partir do conceito de direito moral.

A objeção ao argumento de Shue por direitos básicos falha porque ele recorre ao prazer (enquanto gozo de um direito) para definição do conceito de um direito moral, mesclando a seu argumento analítico razões morais para fundamentar sua argumentação.

Shue segue sua teoria na esteira filosófica de James Griffin, James Nickel e John Tasiolas, que em síntese buscam elaborar suas reflexões em torno de concepções substantivadas dos direitos humanos. Existem inúmeras discussões sobre essas teorias, por exemplo, se sua concepção de vida boa está necessariamente tão vinculada ao contexto que não pode ser universalizada, ou se, pelo contrário, é antes mais tênue do que densa e, por isso, tem muito pouca substância. Além disso, colocam-se questões sobre a derivação de pretensões normativas de direitos a partir de interesses fundamentais.

O pensamento de Shue apesar de suas limitações e inconsistências apresenta uma teoria filosófica razoável e racional que possibilita abordar o tema dos direitos humanos a partir de um ponto de vista moral com consequências econômicas e sociais. O presente artigo pretendeu 
acenar em breves linhas sua contribuição para a defesa e o reconhecimento dos direitos humanos como direitos sociais.

\section{REFERÊNCIAS}

DECLARAÇÃO UNIVERSAL DOS DIREITOS HUMANOS. Disponível em: <http://www.onubrasil.org.br/documentos direitoshumanos.php>. Acesso em 28/05/2016.

FORST, Rainer. Justification and Critique. Cambridge: Polity Press, 2014.

PAYNE, Michael. Henry Shue on Basic Rights. In: Essays in Philosophy. Jun. 2008. n. 2. Vol. 9. SHUE, Henry. Basic Rights. New Jersey: Princeton University, 1980.

WIDDOWS, Heather. Global Ethics. Acumen, Durham U.K., 2011. 